\title{
Towards construction of an ultra high density linkage map for Pinus pinaster
}

\author{
Enrique Ritter ${ }^{a}$, Ana Aragonés ${ }^{\mathrm{a}}$, Torsten Markussen ${ }^{\mathrm{b}}$, Virginie Acheréc, Santiago Espinel ${ }^{\mathrm{a}}$, \\ Matthias Fladung ${ }^{\mathrm{b}}$, Sandra Wrobel ${ }^{\mathrm{b}}$, Patricia Faivre-Rampant ${ }^{\mathrm{c}}$, Sylvain Jeandroz ${ }^{\mathrm{c}}$ \\ and Jean-Michel Favre
}

\author{
a NEIKER, Apartado 46, Vitoria, Alava, 01080, Spain \\ ${ }^{\mathrm{b}}$ BFH, Institute for Forest Genetics, Sieker Landstrasse 2, Grosshansdorf, 22927, Germany \\ ${ }^{\mathrm{c}}$ UMR UHP-INRA Plant-Microbes Interactions, Faculté des Sciences, BP 239, 54506 Vandœuvre-lès-Nancy, France
}

(Received 16 August 2001; accepted 22 February 2002)

\begin{abstract}
Two parental linkage maps have been constructed from the $P$. pinaster reference population $(0024 \times$ C 803$)$ based on AFLP, SSR and EST markers. Although segregating polymorphism was low due to a high degree of homozygosity in the parents, 12 linkage groups with 26 to 46 markers each were obtained for each parent. The availibility of 70 anchor points based on fragments common to both parents and based on codominant SSR and EST markers allowed to determine homologous chromosomes for both maps and to construct one integrated map. Total genome length of the integrated map is around $2000 \mathrm{cM}$ including 1182 markers. Since some of the EST and SSR markers are also mapped in different pine species, association of linkage groups of our reference population with those of other published maps was possible.
\end{abstract}

\section{AFLP, SSR, EST markers / genetic mapping}

Résumé - Vers la construction d'une carte génétique ultra-haute densité chez Pinus pinaster. Deux cartes génétiques ont été construites à partir d'un croisement intra-spécifique de $P$. Pinaster (0024 Landes $\times$ C803 Corse) avec des marqueurs AFLP, SSR et EST. Malgré un faible polymorphisme dû à la forte homozygotie des parents, 12 groupes de liaison comprenant 26 à 46 marqueurs ont été obtenus pour chacune des cartes. La présence de 70 points d'ancrage déterminés à partir des fragments communs aux deux parents a permis d'identifier les chromosomes homologues des deux cartes et de construire une carte consensus d'une longueur totale d'environ $2000 \mathrm{cM}$ et comprenant $1182 \mathrm{marqueurs.} \mathrm{La}$ présence de quelques marqueurs EST et microsatellites déjà cartographiés chez différentes espèces de pins a permis d'aligner un certain nombre de groupes de liaison avec cette carte de pin maritime.

marqueurs AFLP, SSR, EST / cartographie génétique

\section{INTRODUCTION}

Several linkage maps have been produced in a variety of forest species including Pinus. They are based on different marker types such as RFLPs in Pinus taeda [6, 19] and RAPDs in Pinus pinaster [4] and Pinus radiata [7]. Also AFLP maps are available for Pinus pinaster [4] , $P$. radiata [2] and Pinus edulis [22]. Recently a high-density map of $P$. pinaster has been constructed [5]. Other marker types such as proeins and isozymes are integrated in these maps $[4,6,15]$ as well as EST [3] and SSR markers [8] which may be useful for aligning different maps.

In order to apply DNA marker technology in breeding of coniferous species a project has been initiated with the aim of constructing an ultra-high-density linkage map (UHD map) of Pinus pinaster based on several thousands AFLP markers and numerous published microsatellites (SSR). The reference map will be used for comparative genome and QTL analyses in different genetic backgrounds. It is the aim to align other

* Correspondence and reprints

Tel.: 34945121 381; fax: 34945281 422; e-mail: eritter@neiker.net 
published linkage maps in forest species with this reference map. Based on a reduced number of markers, comparative genome and QTL analyses will be performed in different pine species and related gymnosperms.

In this paper we present the first project results, which consist of an integrated linkage map derived from two $P$. pinaster genotypes and some associations of linkage groups of our map with those of different pine species.

\section{MATERIALS AND METHODS}

\subsection{Plant material}

The F1 reference population of $P$. pinaster descended from the cross 0024 Landes $\times$ C803 Corsica. The parental trees had been selected in cooperation by INRA-Pierroton and AFOCEL SW research stations. The cross was performed in 1987 and the 129 resulting progeny trees were established in the field by AFOCEL in 1990. A total of 80 out of the 129 progeny genotypes, established in the AFOCEL experimental stands of Troussas and Arsague (Landes; SW, France), were used for linkage mapping.

\subsection{Molecular methods}

Genomic DNA was extracted from needles using the DNeasy Plant Kit from Qiagen with slight modifications of the supplier's protocol.

AFLP analysis was performed according to [23] using EcoRI/MseI adapters. Preamplification was performed with one selective nucleotide and specific amplification with 3 selective nucleotides $(+1 /+3$ amplification). Also $+2 /+4$ amplifications were performed. Amplification products were separated on 6 or $8 \%$ denaturing polyacrylamide gels. Different techniques were used for detecting amplification products. AFLP fragments were detected on a LI-COR 4200-S1 DNA sequencer using primers labelled with the fluorescent infrared dye IRD800 (LI-COR, Lincoln, Nebraska, USA) or on a ALFexpressII (Amersham Pharmacia Biotech, Germany) with Cy5-Amidite labelled primers (MWG-Biotech, Germany). Analysis was performed according to the manufacturer instructions in each case.

SSR primers developed in different species were analyzed for polymorphism and segregation. SSR developed in Pinus pinaster and P.halepensis [13] in P.strobus ([9, 10]; http://dendrome.ucdavis.edu/Data/echt_ssr_primers.html), in P. radiata and P. sylvestris ([11, 20, 21]; http://dendrome.ucdavis.edu/ Data/hardssr.html) were used for this purpose. Furthermore, several other as yet unpublished SSR primers from Pinus radiata were obtained from Gavin Moran (CSIRO, Australia) and from Craig Echt (Forest Research Inc., New Zealand) and from Picea abies from Giovanni Vendramin (IMGPF, Italy). SSR analysis was performed as described by [13] or based on the information given in the mentioned WEB pages. EST primers were obtained from the information provided on http://www.pierroton.inra.fr/genetics/pinus/ primers.htm. EST analysis was performed according to [12].

\subsection{Data analysis and linkage mapping}

Polymorphic DNA fragments were scored for presence or absence in parents and F1 progenies. Linkage analysis between marker fragments, estimation of recombination frequencies, and determination of linear order between linked loci including multipoint linkage analysis and the EM algorithm for handling missing data were performed as described in [16, 17]. The MAPRF program [17] was applied for the computational methods. Firstly, linkage groups were constructed based on fragments specific to either parent. Linked fragments were arranged into linkage groups using a minimum, commonly accepted LOD threshold of 3.0 between consecutive markers. Subsequently, fragments common to both parents were integrated into linkage groups as anchor points as described in [16]. Only common markers linked with recombination frequencies of zero to at least one parent (LOD > 6) and linked with a minimum LOD threshold of 3.0 to the other parent were considered for this purpose.

\section{RESULTS}

\subsection{Generation of polymorphic DNA markers}

Nearly 300 different primer combinations (PCs) were analyzed for the generation of AFLP-fragments. More than 100 fragments were often produced with specific primer combinations, with from one to 25 segregating fragments in the mapping population. However, some primer combinations produced no segregating fragments. This was generally the case for primer combinations with high AT contents. In general, better quality of gels were obtained with the $+2 /+4$ amplification system.

A total of 239 AFLP primer combinations were used for the molecular analyses and generated 1740 segregating fragments. Thus on average, 7.3 polymorphic bands per primer combination were obtained. Approximately 39\% of the segregating fragments were specific for either one parent of the cross, while $22 \%$ of the fragments were present in both parents. Around 16\% of the fragments showed significant deviations $(\alpha>5 \%)$ from the expected segregation ratios.

Furthermore, a total of 120 SSR and 30 EST primer pairs were used in this study. Amplification products were obtained in most cases after adapting the particular PCR conditions in each case. However, as with AFLP markers, a low degree of polymorphism between parental alleles together with a large degree of homozygosity (i.e. non segregating polymorphic fragments) was observed. Only 21 SSR and 10 EST markers showed one or more segregating bands.

\subsection{Construction of linkage maps}

Initially, individual linkage maps of 12 linkage groups each were obtained for the two parents of the mapping population. Their characteristics are summarised in table I. Details of the maps, parental AFLP profiles as well as the obtained polymorphisms are displayed on the project WEB page (http://www.neiker.net/UHDfor). Linkage groups of the P1 map (parent 0024) contained 26 to 46 individual and common markers each and were between 107.8 and $180.1 \mathrm{cM}$ in length. The total P1 map length (female parent 0024) was 
Table I. Characteristics of the $P$. pinaster maps from the cross $0024 \times \mathrm{C} 803$.

\begin{tabular}{lcccc}
\hline \multicolumn{5}{c}{ P1 - MAP (0024) } \\
\hline LG & Length & IM & CM & TM \\
\hline 1 & 160.4 & 35 & 9 & 44 \\
2 & 153.2 & 28 & 12 & 40 \\
3 & 131.8 & 26 & 9 & 35 \\
4 & 151.2 & 27 & 10 & 37 \\
5 & 146.3 & 27 & 8 & 35 \\
6 & 107.8 & 20 & 6 & 26 \\
7 & 121.5 & 24 & 7 & 31 \\
8 & 135.3 & 22 & 7 & 29 \\
9 & 180.1 & 38 & 8 & 46 \\
10 & 148.7 & 33 & 7 & 40 \\
11 & 149.2 & 27 & 8 & 35 \\
12 & 150.3 & 28 & 7 & 35 \\
\hline
\end{tabular}

\begin{tabular}{cccc}
\multicolumn{4}{c}{ P2 - MAP (C803) } \\
\hline Length & IM & CM & TM \\
\hline 173.3 & 27 & 10 & 37 \\
171.1 & 28 & 10 & 38 \\
174 & 25 & 6 & 31 \\
190.5 & 23 & 7 & 30 \\
187.3 & 30 & 7 & 37 \\
153.7 & 19 & 4 & 23 \\
116.7 & 23 & 6 & 29 \\
130.5 & 22 & 5 & 27 \\
181.5 & 27 & 8 & 35 \\
115.1 & 24 & 7 & 31 \\
175.1 & 24 & 12 & 36 \\
172.7 & 32 & 9 & 41 \\
\hline
\end{tabular}

\begin{tabular}{ccccc}
\multicolumn{5}{c}{ Integrated Map } \\
\hline Length & IM & CM & TM & AP \\
\hline 175.6 & 62 & 12 & 74 & 7 \\
168.9 & 56 & 13 & 69 & 9 \\
176.5 & 51 & 9 & 60 & 6 \\
175 & 50 & 11 & 61 & 6 \\
179.3 & 57 & 11 & 68 & 4 \\
151.5 & 39 & 6 & 45 & 4 \\
123.2 & 47 & 8 & 55 & 5 \\
142.5 & 44 & 8 & 52 & 4 \\
191 & 65 & 10 & 75 & 6 \\
156.5 & 57 & 9 & 66 & 5 \\
182.8 & 51 & 13 & 64 & 7 \\
171.4 & 60 & 10 & 70 & 6 \\
\hline & & & & \\
1994.2 & 639 & 120 & 759 & 70 \\
166.2 & 53.3 & 10 & 63.3 & 5.8 \\
\hline
\end{tabular}

\begin{tabular}{|c|c|c|c|c|c|c|c|c|c|c|c|c|c|}
\hline Total: & 1735.8 & 335 & 98 & 433 & 1941.5 & 304 & 91 & 395 & 1994.2 & 639 & 120 & 759 & 70 \\
\hline Mean: & 144.7 & 27.9 & 8.2 & 36.1 & 161.8 & 25.3 & 7.6 & 32.9 & 166.2 & 53.3 & 10 & 63.3 & 5.8 \\
\hline
\end{tabular}

+217 markers linked with recombination frequencies of zero to other markers +206 associated fragments: Total Markers: 1182

Legend:

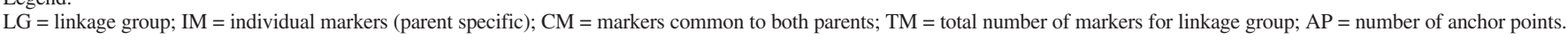

$1736 \mathrm{cM}$. The P2 map (male parent C803) was $1942 \mathrm{cM}$ in length and made up of linkage groups with 23 to 41 markers each. The size of the linkage groups varied between 115.1 and $190.5 \mathrm{cM}$.

Further 217 fragments were linked with recombination frequencies of zero to other fragments in these linkage maps and have not been not considered in these counts.

Linkage to mapped markers on linkage groups was apparent for 206 additional markers. However, these were highly distorted or consisted of common fragments linked to other fragments with reduced LOD values and could not be placed in a single interval with high certainty. Since the standard errors of the estimates of the recombination frequencies were high, these 206 markers are included in this map as so called "associated markers", anchored to the marker with the highest probability.

Based on the integration of 70 markers common to both parents and codominant markers like SSRs and ESTs into linkage groups for both parents, it was possible to assign all 12 homologous chromosomes for P1 and P2, and to obtain in this way an integrated consensus map with a total of 759 markers (table I, figure 1). Linkage groups of the integrated map varied between 123.2 and $191 \mathrm{cM}$ in length and contained between 45 and 74 markers each. Considering the 217 markers linked without recombination to other displayed markers and the 206 associated markers, an integrated map of 1182 markers was achieved with an average of 99 markers per linkage group.

\subsection{Associations of linkage groups between the reference map and other published maps}

The SSR and EST markers amplified one or two loci each with variable number of alleles. A total of 14 SSR (19 loci) and 7 EST markers (7 loci) could be placed on the reference map (figure 1). Since some of them were also mapped in other pine species, an association of several linkage groups from our reference population with those of other published maps was possible. The summarized results are shown in table II.

\section{DISCUSSION}

\subsection{The generation of segregating polymorphic DNA markers}

The pine genome is known to be relatively large and contains large amounts of repetitive elements [24]. Thus a highly increased number of AFLP amplification products can be expected. It is also well known that increased AT contents in the selective nucleotides leads to a higher number of amplification products. However, the resolution of the gel is limited so that different amplification products may comigrate, hiding in this way possible segregating polymorphisms. Therefore using PCs with lower AT content and/or increasing the number of selective nucleotides in the primers to 4 , potentially results in less amplification products, but in higher segregating polymorphisms of variable number of bands with good quality. 

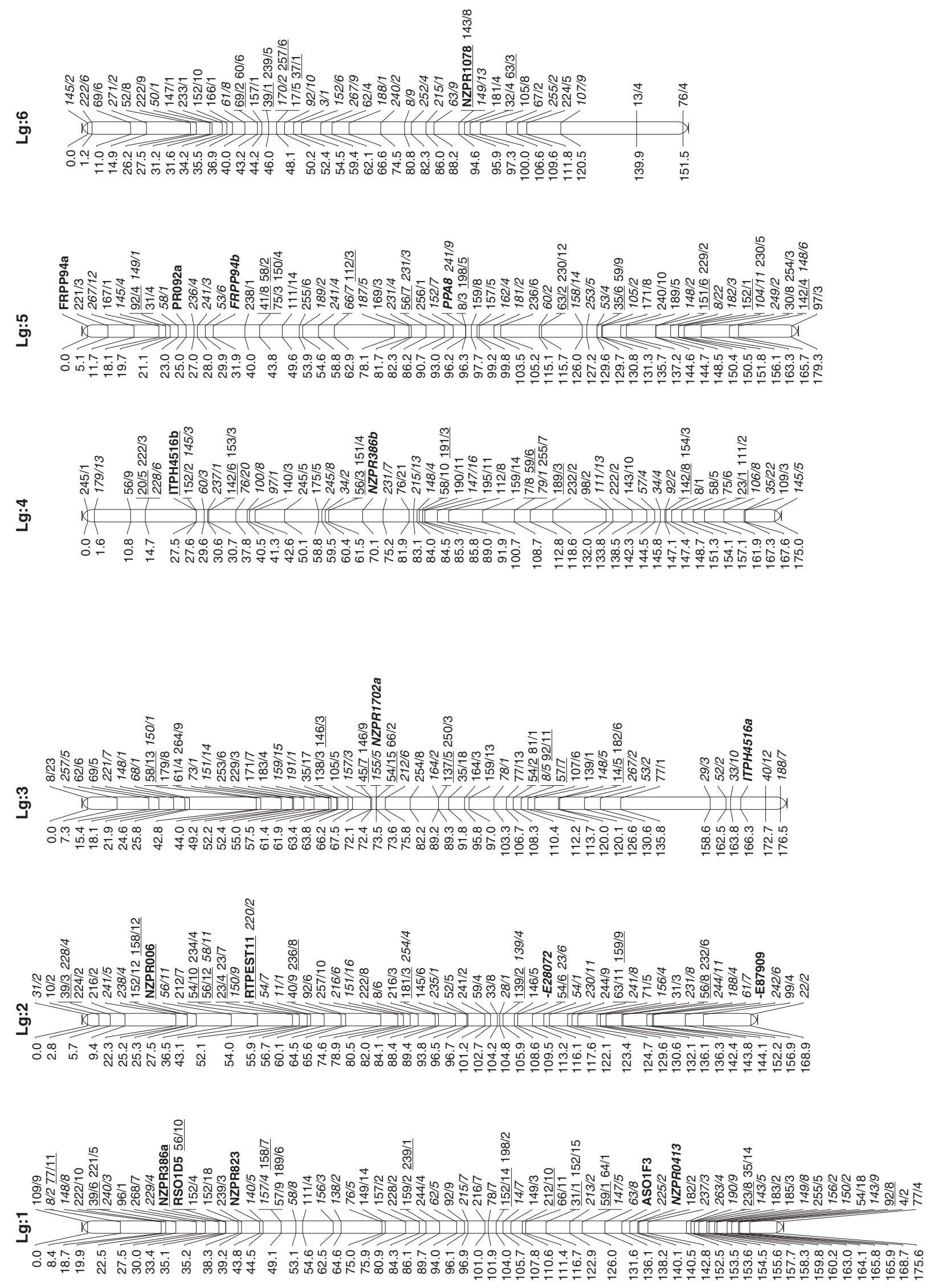

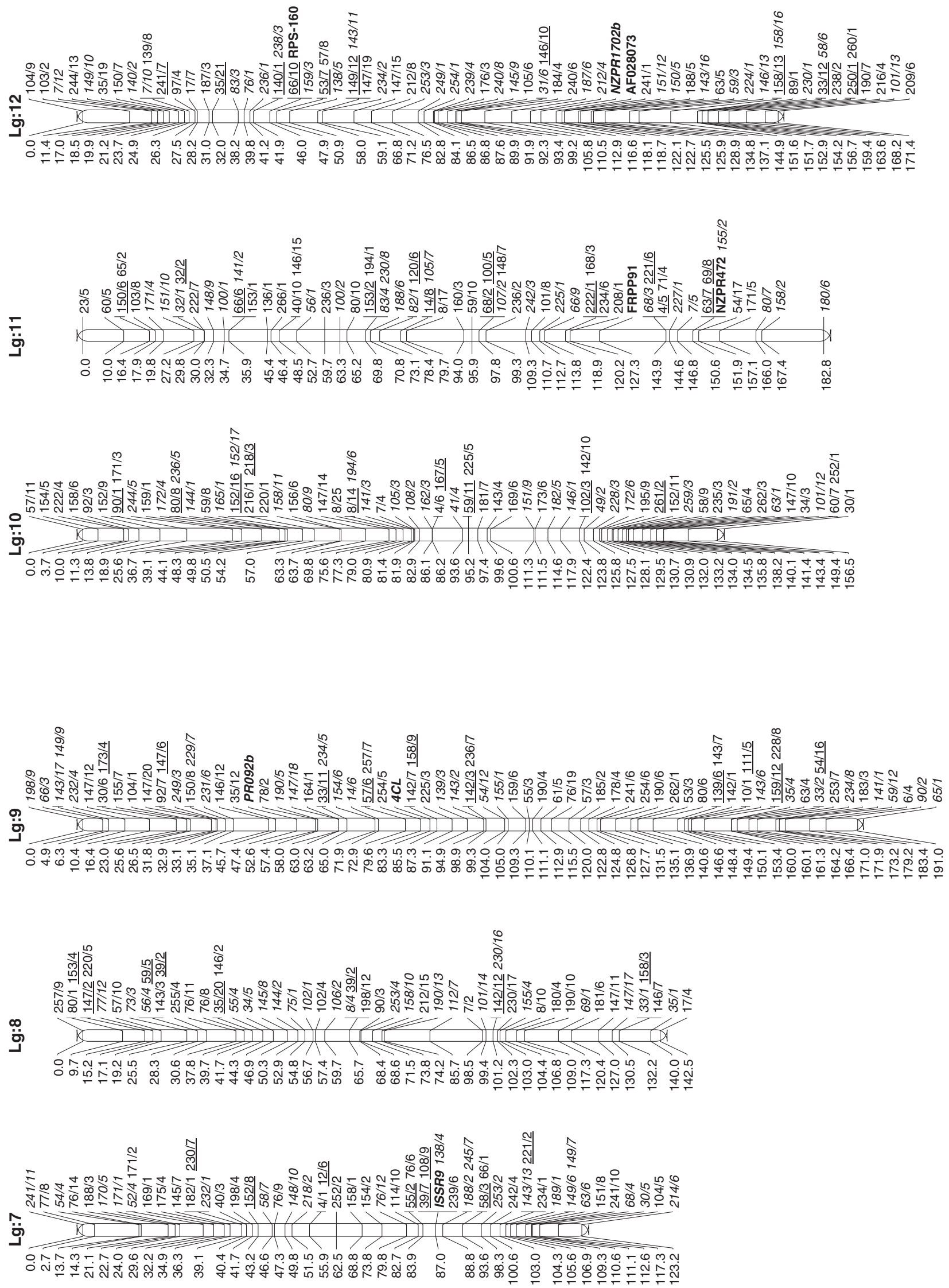
Table II. Locations of mapped SSR and EST markers in our P. pinaster reference map and in other published Pinus maps.

\begin{tabular}{|c|c|c|c|c|c|}
\hline No & Name & Type & Origin & Location in reference map & Location in other published maps \\
\hline 1 & $4 \mathrm{CL}$ & EST & P. taeda & $\operatorname{Lg} 9$ & P. abies $\operatorname{Lg} 6$ (1) \\
\hline 2 & AFO28073 & EST & P. taeda & $\operatorname{Lg} 12$ & P. pinaster $\operatorname{Lg8}(2)$ \\
\hline 3 & ASO1F3 & EST & P. pinaster & $\operatorname{Lg} 1$ & $\begin{array}{l}\text { P. pinaster } \operatorname{Lg} 4(2) \\
\text { P. abies } \operatorname{Lg} 4(1)\end{array}$ \\
\hline 4 & E28072 & EST & P. taeda & $\operatorname{Lg} 2$ & P. pinaster $\operatorname{Lg} 5$ (2) \\
\hline 5 & E87909 & EST & P. taeda & $\operatorname{Lg} 2$ & P. pinaster $\operatorname{Lg} 8$ (2) \\
\hline 6 & PPA8 & EST & P. pinaster & $\operatorname{Lg} 5$ & P. pinaster $\operatorname{Lg} 10(2)$ \\
\hline 8 & FRPP91 & SSR & P.pinaster & $\operatorname{Lg} 11$ & P. pinaster $\operatorname{Lg} 9$ (3) \\
\hline 9 & FRPP94a/b & SSR & P.pinaster & $\operatorname{Lg} 5 / \operatorname{Lg} 5$ & P. pinaster $\operatorname{Lg} 5$ (3) \\
\hline 10 & ISSR9 & ISSR & & $\operatorname{Lg} 7$ & - \\
\hline 11 & ITPH4516a/b & SSR & P.halepensis & $\operatorname{Lg} 3 / \operatorname{Lg} 4$ & P. pinaster $\operatorname{Lg} 3$ (3) \\
\hline 12 & NZPR0413 & SSR & $P$. radiata & $\operatorname{Lg} 1$ & $\begin{array}{l}\text { P. pinaster } \operatorname{Lg} 4(2) \\
\text { P. radiata } \operatorname{Lg} 4(4)\end{array}$ \\
\hline 14 & NZPR1078 & SSR & P. radiata & $\operatorname{Lg} 6$ & $\begin{array}{l}P \text {. pinaster } \operatorname{Lg} 2(2) \\
P . \text { radiata } \operatorname{Lg} 2(4)\end{array}$ \\
\hline 15 & NZPR386a/b & SSR & P. radiata & $\operatorname{Lg} 1 / \operatorname{Lg} 4$ & P. radiata $\operatorname{Lg} 2$ (4) \\
\hline 16 & NZPR472 & SSR & P. radiata & $\operatorname{Lg} 11$ & $\begin{array}{l}\text { P. pinaster } \operatorname{Lg} 1(2) \\
\text { P. radiata } \operatorname{Lg} 1 \text { (4) }\end{array}$ \\
\hline 17 & NZPR006 & SSR & P. radiata & $\operatorname{Lg} 2$ & P. radiata $\operatorname{Lg} 5$ (4) \\
\hline 18 & NZPR823 & SSR & P. radiata & $\operatorname{Lg} 1$ & $\begin{array}{l}\text { P. pinaster } \operatorname{Lg} 5(2) \\
\text { P. radiata } \operatorname{Lg} 5(4)\end{array}$ \\
\hline 19 & PR092a/b & SSR & P. radiata & $\operatorname{Lg} 5 / \operatorname{Lg} 9$ & P. radiata $\operatorname{Lg} 3$ (5) \\
\hline 20 & RPS-160 & SSR & P.strobus & $\operatorname{Lg} 12$ & - \\
\hline 21 & RTPEST11 & SSR & P. taeda & $\operatorname{Lg} 2$ & $P$. pinaster $\operatorname{Lg} 5(2)$ \\
\hline
\end{tabular}

(1) http://www.pierroton.inra.fr/genetics/Picea/

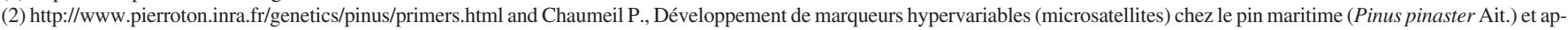
plications en génétique, 2001, DEA Biologie Forestière, Université de Nancy (several markers are only cited in the DEA but will be published on this web site).

(3) Mariette et al., 2001.

(4) $P$. radiata map aligned with $P$. taeda reference population [1]; Phil Wilcox and Craig Echt, personal communication.

(5) Devey et al., 1999.

Independently of these findings, the unexpected low degree of polymorphism of AFLP, SSR and EST markers observed in our progeny is surprising considering the well marked differentiation between the original provenances of the parents [14] and the similar level of genetic diversity encountered in $P$. pinaster and other Pinus species $[9,20]$. Many polymorphic fragments exist between the parents of our mapping population, which represent different ecotypes from Landes and Corsica, respectively. However, a large degree of homozygosity exists, since parent specific fragments do not segregate. This increased homozygosity is probably due to a low degree of biodiversity, which exist at the specific sites (i.e., trees are quite different between sites but very similar within a site).

\subsection{Arrangement of DNA markers into linkage maps}

The analysis of segregating DNA markers established twelve independent linkage groups for the $P$. pinaster genotypes 0024 and C803, respectively (i.e., lateral markers were not statistically linked to any other lateral marker of any other linkage group). These 12 linkage groups may correspond to the 12 chromosomes of the haploid pine genome $(2 n=2 x=24)$. Moreover, the presence of common markers made it possible to identify all homologous chromosomes in each parent. With several common markers present in the same order on chromosomes of both parents, it is possible to combine the information of markers from different individuals as described in [17]. In this way the number of markers available per chromosome can be increased.

The total length of linkage maps did not differ between the parents of the mapping population and is in agreement with other linkage maps obtained in this species. Our $P$. pinaster reference map represents one of the maps with the highest number of markers in forest species.

\subsection{Alignment with other Pinus maps}

Alignment between different linkage maps can be achieved, if identical markers have been used in these maps 
and if comigrating bands map to identical positions. SSR and EST markers are mainly codominant, highly polymorphic and represent powerful tools for different genetic analyses. Since they seem to be conserved among species and to a certain degree also within families, they have been used for mapping and alignment of linkage maps in several forest species $[1,3,8,13]$. We have evaluated numerous SSR and EST markers in our study and several could be used to associate linkage groups in different parents (table II). However, the low level of polymorphism of EST and SSR markers observed in our reference population has led to association of linkage groups between maps. Since this goal is crucial for the usefulness of our map, additional SSR/EST primers will be evaluated in order to achieve a complete alignment.

Alignments between maps were achieved also with comigrating AFLP markers in potato, involving different Solanum species [18]. However, it will be necessary to prove if this is also possible for pine species by comparing parental profiles and map locations of comigrating fragments from AFLP primer combinations which have been used in different mapping populations.

Acknowledgements: This study was supported by EC DGXII under the contract QLK5-CT1999-01159 of the 5th Framework Programme.

\section{REFERENCES}

[1] Brown G.R., Kadel E.E. III, Bassoni D.L., Kiehne K.L., Temesgen B., van Buijtenen J.P., Sewell M.M., Marshall K.A., Neale D.B., Anchored reference loci in loblolly pine (Pinus taeda L.) for integrating pine genomics, Genetics 159 (2001) 799-809.

[2] Cato S.A., Corbett G.E., Richardson T.E., Evaluation of AFLP for genetic mapping in Pinus radiata D. Don., Mol. Breed. 5 (1999) 275-281.

[3] Cato S.A., Gardner R.C., Kent J., Richardson T.E., A rapid PCR-based method for genetically mapping ESTs, Theor. Appl. Genet. 102 (2001) 396-306.

[4] Costa P., Pot D., Dubos C., Frigerio J.-M., Pionneau C., Bodénès C., Bertocchi E., Cervera M., Remington D.L., Plomion C., A genetic map of maritime pine based on AFLP, RAPD and protein markers, Theor. Appl. Genet. 100 (2000) 39-48.

[5] Chagné D., Lalanne C., Madur D., Kumar S., Frigério J.-M., Krier C., Decroocq S., Savouré A., Bou-Dagher-Kharrat M., Bertocchi E., Brach J., Plomion C., A high-density genetic map of maritime pine based on AFLPs, Ann. For. Sci. 59 (2002) 627-636.

[6] Devey M.E., Fiddler T.A., Liu B.-H., Knapp S.J., Neale B.D., An RFLP linkage map for loblolly pine based on a three-generation outbred pedigree, Theor. Appl. Genet. 88 (1994) 273-278.
[7] Devey M.E., Bell J.C., Smith D.N., Neale D.B., Moran G.F., A genetic map for Pinus radiata based on RFLP, RAPD and microsatellite markers, Theor. Appl. Genet. 92 (1996) 673-679.

[8] Devey M.E., Sewell M.M., Uren T.L., Neale D.B., Comparative mapping in loblolly and radiata pine using RFLP and microsatellite markers, Theor. Appl. Genet. 99 (1999) 656-662.

[9] Echt C.S., May-Marquardt P., Hseih M., Zahorchak R., Characterization of microsatellite markers in eastern white pine, Genome 39 (1996) 1102-1108.

[10] Echt C.S., Vendramin G.G., Nelson C.D., Marquardt P., Microsatellite DNA as shared genetic markers among conifer species, Can J. For. Res. 29 (1999) 365-371.

[11] Fisher P.J., Richardson T.E., Gardner R.C., Characteristics of singleand multi-copy microsatellites from Pinus radiata, Theor. Appl. Genet. 96 (1998) 969-979.

[12] Harry D.E., Temesgen B., Neale D.B., Codominant PCR-based markers for Pinus taeda developed from mapped cDNA clones, Theor. Appl. Genet. 97 (1998) 327-336.

[13] Mariette S., Chagné D., Decroocq S., Vendramin G.G., Lalanne C., Madur D., Plomion C., Microsatellite markers for Pinus pinaster Ait., Ann. For. Sci. 58 (2001) 203-206.

[14] Mariette S., Chagné D., Lezier C., Pastuszka P., Raffin A., Plomion C., Kremer A., Genetic diversity within and among Pinus pinaster populations: comparison between AFLP and microsatellite markers, Heredity (2002) in press.

[15] Plomion C., Costa P., Bahrman N., Genetic analysis of needle proteins in Maritime pine 1. Mapping dominant and codominant protein markers assayed on diploid tissue, in a haploid-based genetic map, Silvae Genet. 46 (1997) 161-165.

[16] Ritter E., Gebhardt C., Salamini F., Estimation of recombination frequencies and construction of RFLP linkage maps in plants from crosses between heterozygous parents, Genetics 224 (1990) 645-654.

[17] Ritter E., Salamini F., The calculation of recombination frequencies in crosses of allogamous plant species with application to linkage mapping, Genet. Res. 67 (1996) 55-65.

[18] Rouppe van der Voort J.N.A.M., van Zandvoort P., van Eck H.J., Folkertsma R.T., Hutten R.C.B., Draaistra J., Gommers F.J., Jacobsen E., Helder J., Bakker J., Use of allele specificity of comigrating AFLP markers to align genetic maps from different potato genotypes, Mol. Gen. Genet. 255 (1997) 438-447.

[19] Sewell M.M., Sherman B.K., Neale D.B., A consensus map for loblolly pine (Pinus taeda L.), Genetics 152 (1999) 321-330.

[20] Smith D.N., Devey M.E., Occurrence and inheritance of microsatellites in Pinus radiata, Genome 37 (1994) 977-983.

[21] Soranzo N., Provan J., Powell W., Characterization of microsatellite loci in Pinus sylvestris L, Mol. Ecol. 7 (1998) 1260-1261.

[22] Travis S.E., Ritland K., Whitman T.G., Keim P., A genetic linkage map of Pinyon pine (Pinus edulis) based on amplified fragment length polymorphisms, Theor. Appl. Genet. 97 (1998) 871-880.

[23] Vos P., Hogers R., Bleeker M., Reijans M., Van de Lee T., Hornes M., Frijters A., Pot J., Peleman J., Kuiper M., Zabeau M., AFLP: a new technique for DNA fingerprinting, Nucleic Acids Res. 23 (1995) 4407-4414.

[24] Wakamiya I., Newton R.J., Johnston J.S., Price H.J., Genome size and environmental factors in the genus Pinus, Am. J. Bot. 80 (1993) 1235-1241. 
